\title{
PEGASUS: the Design of an Intervention to Facilitate Shared Decision-making in Breast Reconstruction
}

\author{
A. Clarke $^{1}$ (D) N. Paraskeva ${ }^{1} \cdot$ P. White ${ }^{1} \cdot$ P. Tollow $^{1} \cdot$ E. Hansen ${ }^{2} \cdot$ D. Harcourt ${ }^{1}$ \\ Published online: 28 January 2020 \\ (C) The Author(s) 2020
}

\begin{abstract}
Studies have found varying levels of satisfaction after breast reconstruction surgery with a substantial group of patients reporting some level of regret about their decision. The variable outcomes reported by women undergoing breast reconstruction surgery suggest a role for improved pre-operative communication and shared decision-making (SDM) between patient and health professional. Pragmatic approaches such as decision aids have been evaluated, but the aim of the Patient Expectations and Goals Assisting Shared Understanding of Surgery (PEGASUS) intervention is to facilitate closer interaction between the patient and clinical team. PEGASUS is a standardised two-stage process, in which patients' goals are first elicited, ranked in importance and recorded before being used to frame discussion and decision-making with the surgeon managing care. Following the Medical Research Council (MRC) model, feasibility and acceptability studies have already been reported and a 4-year multicentre randomised controlled trial of 180 participants is underway, (completion 2020). This paper therefore focuses on the design of the intervention itself, in line with recent advice that interventions, in comparison with evaluations, commonly lack a theoretical base and are often under reported. We report a retrospective application of the Capability, Opportunity, Motivation-Behaviour (COM-B) model to provide explicit detail of each step in the intervention design. This is intended to facilitate replication by other clinicians and to provide systematic guidance for others wishing to develop PEGASUS as a strategy for implementing SDM in other clinical populations. Trial Registration: ISRCTN 18000391 (DOI 10.1186/ISRCTN18000391) 27/01/2016.
\end{abstract}

Keywords PEGASUS $\cdot$ Behaviour change $\cdot$ COM-B $\cdot$ Shared decision-making $\cdot$ Breast reconstruction

A. Clarke

alexmacleodclarke@gmail.com

N. Paraskeva

Nicole.Paraskeva@uwe.ac.uk

P. White

Paul.White@uwe.ac.uk

P. Tollow

Pippa.Tollow@uwe.ac.uk

E. Hansen

esther.hansen@nhs.net

D. Harcourt

Diana2.Harcourt@uwe.ac.uk

1 Centre for Appearance Research, University of the West of England, Frenchay Campus, Cold Harbour Lane, Bristol BS16 1QY, UK

2 Royal Free London NHS Foundation Trust, Pond Street, London NW3 2QG, UK

\section{Introduction}

\section{Breast Reconstruction}

Over 5000 women each year in the UK undergo breast reconstruction after mastectomy, with international efforts to increase the uptake of reconstruction including good practice guidelines (UK) and the implementation of the Breast Cancer Patient Education Act (2016). In the USA. however, uptake remains variable in both settings $[1,2]$. Offered as an immediate adjunct to mastectomy or as a delayed procedure, breast reconstruction aims to restore the aesthetics of the breast mound rather than breast function and as such, is aimed at the restoration of quality of life and body image. Relevant patient reported outcomes such as satisfaction with shape, symmetry, sensation and impact on lifestyle are therefore subjective and impacted by individual differences. For example, satisfaction with the appearance of the breast is influenced as much by the level of individual investment in appearance as by the (vertical) symmetry of the breast [3]. There is also substantial evidence from the wider field of body image 
research that objective appearance is not a predictor of psychosocial outcomes [4].

Perhaps not surprisingly therefore, studies have found varying levels of satisfaction after surgery with a substantial group of patients reporting some level of regret about their decision [5]. The National Mastectomy and Breast Reconstruction Audit [1] reported 1/3 of immediate and $22 \%$ of delayed reconstruction patients remained disappointed with outcome at 12 months, with satisfaction with sexual function as low as $52 \%$ for women having immediate breast reconstruction when assessed at 18 months. Not only are a significant number of patients disappointed with the aesthetics of the breast, e.g. visibility of scarring [6] but with impact on their quality of life, e.g. feelings of femininity and sexual activity. The fact that patient expectations may not be met is of concern given the prevailing recommendation that all women should be offered the option of breast reconstruction and the efforts to increase its uptake.

\section{Information and Decision-making}

Good information about the procedure is essential to underpin a complex decision-making process involving discussion of both surgical and individual psychosocial outcomes. Breast reconstruction is an umbrella term for a group of techniques ranging from implant-based reconstruction to the use of multitissue allografts in which tissue is removed from one area of the body (e.g. the abdomen) and grafted with its blood supply to the breast area. The process of breast reconstruction may be carried out in stages and may include creation of new nipple and symmetrisation of the contralateral breast. According to the patient's history and lifestyle, one technique may be more favourable than another including no reconstruction at all.

However, there is an important distinction to be made within health care, between information provision per se, which may be very detailed and thorough, and the process of how the information is used to make a decision, which will be variable [7]. NHS England defines shared decision-making as a process which 'ensures that individuals are supported to make decisions that are right for them. It is a collaborative process through which a clinician supports a patient to reach a decision about their treatment. The conversation brings together: the clinician's expertise, such as treatment options, evidence, risks and benefits and what the patient knows best: their preferences, personal circumstances, goals, values and beliefs'.

Increasingly, many, but not all, patients want information about health care choices and to be fully involved in the decision-making process. How this shared decision-making process is facilitated varies from a simple set of recommended steps $[8,9]$ to the use of decision aids and decision coaching [10]. For example, a recent systematic review evaluated 23 different decision aids designed to assist women in their choice of treatment for early-stage breast cancer, reporting no differences between delivery via Internet, audio, booklet or video modalities [11]. However, decision aids are commonly designed for self-completion and whilst providing information, do not directly facilitate the reciprocal interchange of information via a conversation between surgeon and patient as indicated in the NHS England explanation (above). Notwithstanding the disagreement about how best to define and implement shared decision-making, the considerable evidence of a positive relationship between patient involvement in the decision-making process and high levels of satisfaction has driven the move to embed shared decision-making throughout the health care setting in the UK $[12,13]$. In line with these developments, shared decision-making has potential utility for women considering breast reconstruction, with the following factors of particular relevance:

1) Satisfaction with outcome is the key target for change

2) Shared decision-making is associated with positive outcomes

3) Both aesthetic and individual psychosocial goals must to be understood in assessing expectations of outcome

4) Breast reconstruction involves complex decision-making

We, therefore, designed an intervention (Patient Expectations, and Goals Assisting Shared Understanding of Surgery (PEGASUS)) as a response to the National Mastectomy and Breast Reconstruction Audit [1] with the goal of improving outcomes by developing a shared decision-making model to manage expectations and underpin surgical planning.

\section{Design and Development of Interventions}

The development and evaluation of interventions to change health behaviours is a topic receiving considerable current attention, with acknowledgement that these are often multicomponent processes involving complex interaction between patients, health professionals and contextual factors [14]. Various models have been suggested to support evidence based systematic approaches to their development. For example, the MRC model for development and evaluation of complex interventions [15-17] is widely used but has been criticised for its focus on the evaluation process rather than the specific content of an intervention; a simple and pragmatic series of six steps with more detailed recommendations on content design (Six Steps in Quality Intervention Design 6SquID) has been suggested as an alternative [14]. However, the most comprehensive approach to development of interventions to support behaviour change is the COM-B model $[18,19]$. This model uses an associated taxonomy of behaviour change techniques and has got a considerable body of work supporting its use in clinical settings (http://www.bcttaxonomy.com/interventions). Both 6SquID and COM-B 
address the question of which potential targets for change are the most easily measured, are valid in addressing the underlying problem and which behaviour change techniques have the potential for greatest impact. COM-B also offers the potential to clarify the content of the intervention very clearly so that the process of shared decision-making is made explicit.

In developing our intervention PEGASUS, we followed the MRC model for complex interventions, developing the content systematically, refining and testing in practice, collecting feedback from patients and health professionals as per the model, before carrying out a feasibility and acceptability study [20] prior to a randomised controlled trial (RCT). However, the considerable current interest in the approach following this first publication requires a systematic and more thorough description of the development of PEGASUS in order to allow other researchers to develop modifications for other patient groups. We note the precedent of using COM-B retrospectively in coding BCTTv1 as part of the Theories and Techniques of Behaviour Change Project (www.ucl.ac.uk/ health-psychology/research/TaT) and have therefore used COM-B in a retrospective application to describe the development of PEGASUS as clearly as possible, to identify any potential additions and to facilitate further development.

The COM-B model proposes that behaviour is determined by three components: for any behaviour to be enacted, an individual needs to be motivated to engage in the behaviour, have the opportunity to do so and be capable of doing so. Each of these sources of behaviour is further divided to distinguish between physical and social opportunity, automatic and reflective motivation and physical and psychological capability.

These sources of behaviour form the hub of the Behaviour Change Wheel (BCW) [19], forming an inner ring. There are nine intervention functions (categories of inputs aiming to change behaviour) forming the middle ring. These are education, persuasion, incentivisation, coercion, training, enablement, modelling, environmental restructuring and restrictions. Seven policy categories form the final ring: service provision, regulation, fiscal measures, guidelines, environmental/social planning, communication/marketing and legislation. Having identified the problem behaviour and the target behaviours that support and maintain it, intervention functions and policy categories are selected which are thought to have the best potential utility for achieving change.

\section{Method}

The steps taken to design PEGASUS can be summarised using the $\mathrm{BCW}$, in eight steps:

First, the problem was identified, specified and defined as a behaviour that could be measured. Second, a target behaviour was chosen which had the highest potential for impacting on the problem. This was then specified, including how and when this behaviour was enacted, who would do it and where it would take place. Identifying what needed to change depended on careful assessment of current practice, discussion with the staff involved and the existing and potential barriers. The $\mathrm{BCW}$ was then used to identify the intervention functions (specific behavioural inputs) and potential policy categories with the greatest utility in achieving change. In the last two steps, specific behaviour change techniques were identified and fully described and the design and delivery of PEGASUS was finalised for testing.

\section{Results}

\section{Identify, Define and Specify the Problem Behaviour}

The problem behaviour and the key outcome measure in this study is 'dissatisfaction with outcome of breast reconstruction as expressed on the Breast-Q' [21]. This definition was achieved using the National Mastectomy and Breast Reconstruction Audit [1] as a data source. The national audit recruited 18,216 individuals from all NHS sites providing a service, over a 15 -month period. Outcome data included clinician reported and patient reported outcomes using standardised measures. It therefore represents a substantial and robust data source from which to identify the problem. This decision was made in discussion with three clinical psychologists working with the client group and instrumental in the development of PEGASUS as a response to the audit findings.

\section{Select Target Behaviours}

Target behaviours are those activities that are selected for change in order to impact on the problem behaviour. (For example, if the problem behaviour is smoking, then target behaviours might include avoidance of venues where people are smoking). Target behaviours need to be both observable and measurable. For this reason, despite noting its importance, other researchers [22] have avoided a focus on shared decision-making because of the problems with definition and measurement. (Shared decisionmaking involves multiple behaviours in both the patient and clinician groups). However, there was a strong consensus among the psychologists working within breast care that shared decision-making had both high potential utility in impacting patient satisfaction and also high face validity for both patients and health professionals participating in the intervention. Therefore shared decision-making was operationalised by breaking it down into a series of constituent behaviours which can be said to support the process (Table 1). These behaviours are not intended as an exhaustive list, or as a complete definition of shared decisionmaking, but as a summary of behaviours that are potentially important, observable and achievable and can be said to support a shared decision-making process in breast reconstruction. 
Table 1 Determinants of patient satisfaction after breast reconstruction and potential target behaviours underpinning shared decision-making

Determinants of patient satisfaction after breast

reconstruction (summarised from National Audit 2011)
Potential target behaviours

Explain PEGASUS approach to shared decision-making

- Role of health professional

- Role of patient

Elicit information from patient:

- The cancer journey so far

- Experience of care

- Expectations of outcome of breast reconstruction (aesthetic, psychosocial and process)

Introduce expert information to discuss and modify expectations where appropriate

Elicit, rate importance and record patient goals

- Aesthetic and surgical

- Psychosocial and lifestyle

Use PEGASUS sheet to record:

- Exchange information

- Inform and frame surgical planning

- Discuss and modify expectations if appropriate

- Prompt and use as reminder at home and with relatives

- Inform final decision about surgery
The COM-B model suggests selecting only those behaviours that are the easiest to measure and have the greatest potential utility for achieving change; however, since all the behaviours above were considered achievable and likely to have impact, all were included in the intervention.

\section{Specify Target Behaviours}

The third stage in the process of delivering COM-B requires the specification of the target behaviours; i.e. exactly what is being done, how often, when and by whom. PEGASUS was constructed as a two-stage process involving a first session with a coach (either a psychologist or breast care nurse according to current practice in the clinic) and a second session with the surgeon (Table 2).

\section{Identify What Needs to Change via COM-B Analysis}

The next step involves an assessment of which of the sources of behaviour (capability, opportunity and motivation) need to change for each group of participants. For shared decision-making, this means the patient and the health professional involved. The psychologists working on the development of the intervention made this selection based on their experience of current clinical practice in one major centre. Given the way in which usual care was organised, patients and surgeons already had the opportunity to share decision-making in that the care pathway was already set up with clinic appointments arranged. Both parties were physically capable of carrying out the intervention but input to modify psychological capability was a clear priority.
Thus, patients needed to have appropriate information and to be able to distinguish between surgical outcomes and psychosocial and short and long-term goals. Surgeons needed to understand and remember the process, modify their usual way of working and make plans for dealing with competing priorities. Both coach and surgeon needed to trouble shoot by developing if ...then rules (e.g. if the patient is finding it hard to follow the process then I will use another patient example; if the photocopier is broken then I can copy the record after the clinic and organise sending to the patient). Both aspects of motivation are important. Automatic motivation is important to establish new habits and routines so that the intervention is completed systematically. Reflective motivation, as here, is often a critical component of complex interventions. In this setting both surgeon and patient are being asked to reflect on specific individual goals for surgery. Each has the task of informing the other about their perspective, the patient explaining why and how they believe surgery can help them, the surgeon reflecting on what is achievable (e.g. a particular size of breast), or what is less predictable or outside their control (feeling more feminine), i.e. modifying expectations where needed. The final shared decision depends on reviewing the importance of the goals the patient has identified and using a written record of the process to assist a surgical plan.

\section{Identify Intervention Functions}

Once the relevant sources of behaviour have been identified, the behaviour change wheel is used to select the intervention functions most relevant to achieve change. 
Table 2 Specification of target behaviours

\begin{tabular}{|c|c|c|c|c|c|c|}
\hline Target behaviour & $\begin{array}{l}\text { Who needs } \\
\text { to do the } \\
\text { behaviour? }\end{array}$ & $\begin{array}{l}\text { What do they have } \\
\text { to do differently? }\end{array}$ & $\begin{array}{l}\text { When do } \\
\text { they do it? }\end{array}$ & $\begin{array}{l}\text { Where do } \\
\text { they do it? }\end{array}$ & $\begin{array}{l}\text { How } \\
\text { often do } \\
\text { they do it? }\end{array}$ & $\begin{array}{l}\text { With } \\
\text { whom do } \\
\text { they do it? }\end{array}$ \\
\hline $\begin{array}{l}\text { Elicit patient experience } \\
\text { of cancer journey so far }\end{array}$ & Coach & $\begin{array}{l}\text { Ask questions and reflect back } \\
\text { before providing information }\end{array}$ & $\begin{array}{l}\text { At the first } \\
\text { meeting }\end{array}$ & $\begin{array}{l}\text { In the breast } \\
\text { clinic }\end{array}$ & Once & Patient \\
\hline Provide information & Coach & $\begin{array}{l}\text { Differentiate information about } \\
\text { surgical, psychosocial and } \\
\text { process outcomes }\end{array}$ & $\begin{array}{l}\text { At the first } \\
\text { meeting }\end{array}$ & $\begin{array}{l}\text { In the breast } \\
\text { clinic }\end{array}$ & Once & Patient \\
\hline Explain shared decision making & Coach & $\begin{array}{l}\text { Outline the role of the health } \\
\text { professional and the role } \\
\text { of the patient }\end{array}$ & $\begin{array}{l}\text { At the first } \\
\text { meeting }\end{array}$ & $\begin{array}{l}\text { In the breast } \\
\text { clinic }\end{array}$ & Once & Patient \\
\hline $\begin{array}{l}\text { Elicit patient understanding } \\
\text { and expectations }\end{array}$ & Coach & $\begin{array}{l}\text { Differentiate surgical (aesthetic) } \\
\text { and psychosocial expectations }\end{array}$ & $\begin{array}{l}\text { At the first } \\
\text { meeting }\end{array}$ & $\begin{array}{l}\text { In the breast } \\
\text { clinic }\end{array}$ & Once & Patient \\
\hline Record and rank goals & Coach & $\begin{array}{l}\text { Write down patient goals } \\
\text { differentiating surgical and } \\
\text { psychosocial goals } \\
\text { Rate importance of each } \\
\text { goal from } 0 \text { to } 10\end{array}$ & $\begin{array}{l}\text { At the first } \\
\text { meeting }\end{array}$ & $\begin{array}{l}\text { In the breast } \\
\text { clinic }\end{array}$ & Once & Patient \\
\hline Share information with patient & Coach & Provide copy of the written record & $\begin{array}{l}\text { At the first } \\
\text { meeting }\end{array}$ & $\begin{array}{l}\text { In the breast } \\
\text { clinic }\end{array}$ & Once & Patient \\
\hline Discuss the surgical decision & Surgeon & $\begin{array}{l}\text { Use the written record to frame } \\
\text { discussion of potential surgery }\end{array}$ & $\begin{array}{l}\text { At the second } \\
\text { meeting }\end{array}$ & $\begin{array}{l}\text { In the breast } \\
\text { clinic }\end{array}$ & Once & Patient \\
\hline \multirow[t]{2}{*}{ Set expectations } & Surgeon & $\begin{array}{l}\text { Identify which patient goals are } \\
\text { most directly to be impacted by } \\
\text { surgery (aesthetic) and which } \\
\text { least (psychosocial) }\end{array}$ & $\begin{array}{l}\text { At the second } \\
\text { meeting }\end{array}$ & $\begin{array}{l}\text { In the breast } \\
\text { clinic }\end{array}$ & Once & Patient \\
\hline & & $\begin{array}{l}\text { Rate probability of achieving } \\
\text { surgical goals }\end{array}$ & $\begin{array}{l}\text { At the second } \\
\text { meeting }\end{array}$ & $\begin{array}{l}\text { In the breast } \\
\text { clinic }\end{array}$ & Once & Patient \\
\hline \multirow[t]{2}{*}{ Plan next steps } & Surgeon & $\begin{array}{l}\text { Share record of consultation } \\
\text { with patient }\end{array}$ & $\begin{array}{l}\text { At the second } \\
\text { meeting }\end{array}$ & $\begin{array}{l}\text { In the breast } \\
\text { clinic }\end{array}$ & Once & Patient \\
\hline & & Jointly agree a treatment plan & $\begin{array}{l}\text { At the second } \\
\text { meeting }\end{array}$ & $\begin{array}{l}\text { In the breast } \\
\text { clinic }\end{array}$ & Once & Patient \\
\hline
\end{tabular}

Education is the first important concept for this intervention. Patients considering breast reconstruction are routinely provided with information, but for shared decision-making to be effective, how the information is used to support the process must be understood. Therefore, health professionals needed to understand the PEGASUS model and how to embed it within their practice. Persuasion was necessary to change routine health professional practice. Training was important, with modelling from another team member (either via sitting in for the clinic or via video taped session to demonstrate the process). Although it is possible that a surgeon could carry out the whole PEGASUS process in one rather than two stages, enabling the final decision-making process to be built on an earlier explorative session with a coach provided a way of promoting shared decision-making within the whole clinic team. Therefore the final intervention functions selected by the psychologists developing the intervention were: education, persuasion, training, modelling and enablement.

\section{Identify Policy Categories}

No policy categories were selected during the early development of this intervention. The most likely candidate according to the behaviour change wheel could have been service provision, but since patients in this particular centre were already offered a psychology appointment as part of the routine assessment for breast reconstruction, no service changes were required; indeed, the intervention was deliberately designed so that no additional costs would be incurred during the development phase. In other settings, changes in service provision (e.g. an additional session with a coach) should be considered.

\section{Identify Behaviour Change Techniques}

Specific behaviour change techniques (BCTs) to deliver the intervention functions were identified using the behaviour change techniques taxonomy (BCTTv1) which classifies 93 discrete behaviour change techniques in 19 different categories. Our example script (for stage one), which had been role played and videoed to support training, was analysed to identify all BCTs by cross-reference to the taxonomy.

Table 3 summarises all the BCTs observed. Of these, those selected as essential components of PEGASUS were 1.2 goal setting (behaviour), 1.2 problem solving, 1.3 goal setting (outcome), 1.4 action planning, 1.7 review outcome goals, 4.2 
Table 3 Analysis of the behaviour change techniques being used within the PEGASUS intervention

\begin{tabular}{|c|c|c|}
\hline No. & Behaviour change & Session 1: coach \\
\hline & & $\begin{array}{l}\text { Target behaviour: elicit and agree a } \\
\text { written record of the factors influencing } \\
\text { the decision to have BR }\end{array}$ \\
\hline & Label & Examples \\
\hline
\end{tabular}

1.1 Goal setting (behaviour) $\quad \begin{aligned} & \text { Generate discussion with the patient of their current } \\ & \text { understanding and the expectations that underpin their } \\ & \text { decision to have BR surgery with specific focus on both } \\ & \text { expectations of physical and psychosocial factors }\end{aligned}$

1.2 Problem solving

1.3 Goal setting (outcome)

1.4 Action planning

1.5 Review behaviour goal(s)

1.7 Review outcome goal(s)

$1.9^{\mathrm{a}} \quad$ Commitment

2.4 Self-monitoring of outcome(s) of behaviour

3.1 Social support (unspecified)

3.2 $2^{\mathrm{a}} \quad$ Social support (practical)

Social support (emotional) Ask the patient to consider taking a partner or friend with them to their surgical appointment

4.2 Information about antecedents

4.3 Re-attribution

$5.1 \quad$ Information about health consequences
Identify specific factors that are important for them including expectations of physical appearance and psychosocial consequences including wearing a prosthesis

Prompt the patient to identify barriers preventing them from making a decision such as weighing up the pros and cons, need for more information etc.

Summarise in writing and rate importance of each specific physical and psychosocial goal for the individual on the PEGASUS form

Encourage a plan to review the PEGASUS form with friends or family and revise if needed. Set a time for doing so

Ask patient to take PEGASUS form to appointments with the surgeon

Show the PEGASUS form to the surgeon

eview goals if patient is seen for a second appointment (NB: most are seen only once) a strong commitment (i.e. 'I will bring the form to my next appointment and show it to the surgeon')

Encourage the patient to record any additional factors that occur to them or that emerge in discussion with others

Encourage the patient to look at the PEGASUS sheet again before the appointment with surgeon to ensure that all factors are still relevant and included support where relevant

Encourage the patient to consider what help the individual might need (e.g. opportunity to talk things through with other people, coming with them to an appointment) and how this might be provided

Review previous decisions and personal resources used to come to difficult decisions in general

For example, patient using incorrect information to bias decision-making, e.g. If the person attributes the need for BR to full recovery from cancer, reintroduce the idea that cancer is treated differently and many women choose not to have BR without compromising recovery

Encourage patient to make full use of all information resources
Session 2: surgeon

Target behaviour: use the PEGASUS

written record to inform and discuss options about BR and to make (and record ) the final decision

Examples

Reintroduce the PEGASUS sheet as the basis for discussing options and sharing information about surgery

Ask whether there have been any changes since previous consultation

Explain that the purpose of the session is to make a final decision about surgery and plan next steps

Ask if the patient requires more information

Discuss the different options available on the basis of the history and clinical examination, together with the expectations and preferences of the patient set out on the PEGASUS form

Offer advice and modify expectations as appropriate

Summarise the decision with the patient

Record the decision

Encourage a plan to review the decision with friends or family and revise if needed. Set a time for doing so. Offer follow-up appointment

or

Book patient for next step towards surgery/discharge Review decision if patient is seen for a second appointment (NB: most are seen only once)

Review the factors listed on the PEGASUS sheet as determined in session 1

Consider modifying surgical decision in light of the importance of goals ranked on PEGASUS form, e.g. if physical activities using the arms are rated as highly important (such as tennis) ensure that patient is aware of implications of one BR procedure $\mathrm{v}$ another

Ask the person to use an 'I will' statement to affirm or reaffirm Ask the person to use an 'I will' statement to affirm or reaffirm

Consider introduction to support groups and advise sources of Support attendance at support group where relevant a strong commitment (i.e. 'I will give up smoking before being added to surgical list')

If a decision is proving difficult, encourage the patient to consider what help the individual might need (e.g. opportunity to talk things through with other people, coming with them to an appointment) and how this might be provided

For example, patient using incorrect information to bias decision-making, e.g. If the person attributes the need for $\mathrm{BR}$ to full recovery from cancer, reintroduce the idea that cancer is treated differently and many women choose not to have BR without compromising recovery

Direct patient to appropriate sources of information

Consider the use of a decision aid

Encourage patient to make full use of all information resources

Direct patient to appropriate sources of information Discuss the outcome of using a decision aid if appropriate 
Table 3 (continued)

$\begin{array}{lll}\text { No. Behaviour change } & \text { Session 1: coach } & \text { Session 2: surgeon } \\ \text { techniques } & \begin{array}{l}\text { Target behaviour: elicit and agree a } \\ \text { written record of the factors influencing } \\ \text { the decision to have BR } \\ \text { Examples }\end{array} & \begin{array}{l}\text { Target behaviour: use the PEGASUS } \\ \text { written record to inform and discuss options about BR } \\ \text { and to make (and record ) the final decision }\end{array} \\ & \text { Examples }\end{array}$

5.3 Information about social
$\begin{gathered}\text { Explain that satisfaction with decision-making is higher if } \\ \text { and environmental } \\ \text { consequences }\end{gathered}$ $\begin{aligned} & \text { people carefully consider all the factors that are important } \\ & \text { to them and the probability that these can be achieved }\end{aligned}$

5.4 Monitoring of emotional Encourage patient to reflect on how they would feel in the consequences future if they take time to consider all the reasons that BR might be important for them and the likely outcomes

5.5 Anticipated regret

5.6 Information about emotional consequences 6.1 Demonstration of the
behaviour

6.2 Social comparison

6.3 Information about others' approval

7.1 Prompts/cues

9.1 Credible source

9.2 Pros and cons cons of having surgery
9.3 Comparative imagining of Prompt the person to imagine and compare likely or possible future outcomes

10.9 Self-reward

\subsection{Reduce negative emotions $^{\mathrm{a}}$}

11.3 Conserving mental resources

12. Antecedents

12.1 Restructuring the physical Encourage patient to think about a quiet time when they will environment

12.6 Body changes

13.1 Identification of self as role model
Ask the person to assess the degree of regret they will feel if they believe that they did not consider all the factors important for them in considering BR

Explain that physical changes do not necessarily result in psychosocial changes (e.g. 'feel a whole woman'). Taking time to elicit all the factors that are important for an individual is an important part of the process of coming to a decision and likely to result in higher satisfaction with the final decision made

Use video example or case histories to model how different women have different priorities in considering the factors important in considering BR

Draw attention to the fact that women have different priorities and expectations in coming to a decision about whether to have $\mathrm{BR}$

Use case histories to illustrate the reaction of other people to the factors people consider important in weighing up whether to have BR

Discuss the time and place that the patient may choose to review the factors important in decisions about BR and ? discuss with another person

Use of examples such as Angelina Jolie but discuss in terms of the factors she will have considered in thinking about surgery, not the decision itself

See section 5

NB: this is pros and cons of making the decision not pros and preferences for BR for them rather than generic guidance

Encourage to reward self with material (e.g. new clothes) or other valued objects if and only if they have clearly progressed decision-making, e.g. discussed with partner

Advise on the use of stress management skills, e.g. relaxation, pacing of activities

Advise to consider decision-making at certain times in the week rather than constant rumination

not be interrupted in order to discuss decision-making with partner/friend (e.g. arrange baby sitter, or ask person specifically to come to discuss this issue)

Prompt healthy eating, relaxation and exercise as alternative ways of improving positive self concept and confidence in ability to make decisions

Inform the person that taking time to consider all the factors important to them in making a decision creates a powerful role model for others in the family and friends who may face the same challenge outcomes following a full assessment of their individual
Explain that the consequences re cancer are the same whether $\mathrm{BR}$ is undertaken or not

Encourage patient to make the decision for her that is consistent with her values and beliefs set out in PEGASUS

Encourage patient to reflect on how they would feel in the future if they make a decision which is concordant with the preferences and expectations they have about BR

Ask the person to assess the degree of regret they will feel if they believe that they made a decision that was inconsistent with the all the factors important for them in considering BR or failed to make a decision

Explain that physical changes do not necessarily result in psychosocial changes (e.g. 'feel a whole woman'). Making a decision which is concordant with the preferences and expectations they have about BR is likely to result in higher satisfaction with the final decision made whether or not the final choice

is to have BR or not

Use video example or case histories to model women making different decisions about BR

Draw attention to the fact that women make different decisions about whether or not to have BR

Use case histories to illustrate the reaction of other people to different decisions that patients make (NB: partners may be relieved that further surgery is being avoided)

Consider making a further appointment $\mathrm{f}$ the patient is unable to reach a decision

Use of examples such as Angelina Jolie but point out that other people make different choices with which they are equally satisfied

Use the weightings for each goal on the PEGASUS sheet to help the patient identify the importance of each outcome for her and the probability of achieving this via surgery

Prompt the person to imagine and compare likely or possible outcomes having made a fully informed decision based on their individual preferences versus generic guidance

nform the person that making a decision either for or against surgery creates a powerful role model for others in the family and friends who may face the same challenge, regardless of whether BR is chosen 
Table 3 (continued)

\begin{tabular}{|c|c|c|c|}
\hline \multirow[t]{2}{*}{ No. } & Behaviour change & Session 1: coach & Session 2: surgeon \\
\hline & Label & $\begin{array}{l}\text { Target behaviour: elicit and agree a } \\
\text { written record of the factors influencing } \\
\text { the decision to have BR } \\
\text { Examples }\end{array}$ & $\begin{array}{l}\text { Target behaviour: use the PEGASUS } \\
\text { written record to inform and discuss options about BR } \\
\text { and to make (and record ) the final decision } \\
\text { Examples }\end{array}$ \\
\hline 13.2 & Framing/reframing & $\begin{array}{l}\text { Suggest that the person might think of the process of eliciting } \\
\text { more information about BR as reducing stress about future } \\
\text { decision-making rather than increasing it }\end{array}$ & $\begin{array}{l}\text { Suggest that the person might think of making } \\
\text { a decision about BR as reducing stress rather than } \\
\text { increasing it, whatever the choice made }\end{array}$ \\
\hline 13.3 & Incompatible beliefs & $\begin{array}{l}\text { Draw attention to any difficult decisions made in the past, e.g. } \\
\text { change of job, relationship etc. }\end{array}$ & \\
\hline 15.1 & $\begin{array}{l}\text { Verbal persuasion } \\
\text { about capability }\end{array}$ & $\begin{array}{l}\text { Encourage the person that they can successfully identify and } \\
\text { weigh up the important factors in making this decision as } \\
\text { they did in all the other stages } \\
\text { of the cancer journey }\end{array}$ & $\begin{array}{l}\text { Encourage the patient to believe that they can make a decision } \\
\text { that is right for them provided they think about all the } \\
\text { reasons that underpin it and act in accordance with these } \\
\text { factors }\end{array}$ \\
\hline 15.2 & $\begin{array}{l}\text { Mental rehearsal } \\
\text { of successful } \\
\text { performance }\end{array}$ & $\begin{array}{l}\text { Advise to imagine how they will feel once the decision has } \\
\text { been fully explored and summarised }\end{array}$ & $\begin{array}{l}\text { Advise to imagine how they will feel once the } \\
\text { decision has been made }\end{array}$ \\
\hline 15.3 & Focus on past success & $\begin{array}{l}\text { Advise to describe or list the occasions on which } \\
\text { the person has had to inform themselves about making a } \\
\text { difficult decision }\end{array}$ & $\begin{array}{l}\text { Encourage patient to consider previous occasions } \\
\text { when they made a difficult decision } \\
\text { and the factors that assisted them }\end{array}$ \\
\hline
\end{tabular}

${ }^{\mathrm{a}} \mathrm{BCTs}$ with potential utility in future developments of PEGASUS

information about antecedents, 4.3 re-attribution, 5.1 information about health consequences, 5.3 information about social and environmental consequences, 5.6 information about emotional consequences, 6.2 social comparison and 9.2 pros and cons. Additional BCTs were observed but were not considered an essential component of the intervention; they may or may not be used as part of any consultation depending on individual presentation. Potentially useful additions to PEGASUS identified in the taxonomy included: 1.9 commitment, ask the patient to use an 'I will' statement to affirm or reaffirm a strong commitment (i.e. I will bring the form to my next appointment)' and 3.2 social support, encourage the patient to consider what help they might need.

\section{Design of the Intervention Including Setting, Frequency and Staff Training}

PEGASUS has been delivered as part of an existing current clinical pathway [20]. Table 4 illustrates the final intervention design, set out as a summary of actions for those delivering PEGASUS.

In intervention stage 1, the patient meets with a PEGASUS coach. In intervention stage 2 , the same patient meets with the surgeon managing their care who uses the information elicited in intervention stage 1 to frame the discussion of surgery. Appointments can be same day (for women travelling longer distances) to 2 weeks as per usual care pathway. Because the intervention has an output, i.e. is recorded on the PEGASUS sheet, progress can be regularly reviewed to check that the steps in each stage of PEGASUS are being followed as intended. A detailed manual and video of an example intervention are available to make this detail explicit (contact author). Finally, sessions are recorded for review to ensure fidelity of the intervention during the evaluation phase.

\section{Discussion and Conclusion}

The COM-B model provides a logical and systematic model to describe the design of a complex intervention for supporting shared decision-making in breast reconstruction. We made use of a substantial data source (National Mastectomy and Breast Reconstruction Audit) to identify a problem (patient dissatisfaction after breast reconstruction) followed by the design of an intervention to improve these patient outcomes which was developed and is undergoing systematic evaluation in line with the MRC model for complex interventions. Whilst 'patient dissatisfaction' can be criticised for being an outcome rather than a behaviour, it is closely associated with behaviours such as avoidance of intimacy, changes in lifestyle choices (type of clothing) and requests for additional surgery; thus it is a key patient reported factor in assessing the utility of surgery and was readily available via the audit [1].

This paper describes a retrospective fit of the COM-B model to provide explicit detail of each step in the intervention design. There are a number of criticisms that can be made of this. Clearly, a prospective approach would have 
Table 4 A COM-B theory-based design of an intervention designed to support shared decision-making for women considering breast reconstruction (PEGASUS)

Step Action

Stage 1: the meeting between the patient and the trained PEGASUS coach; the key components ${ }^{\mathrm{a}}$

Step 1 Introduce the PEGASUS intervention.

1.1. What does PEGASUS stand for?

1.2. Audit findings; unmet expectations.

Step 2 'You know you'-you are the expert on your life.

Step 3 Brief overview of the patient's pathway.

Step 4 Explain how this session will work.

4.1. Check patient understands the purpose of the session.

Step 5 Elicit the patient's surgical goals and write them down on the PEGASUS sheet.

Step 6 Explain the rating system and ask the patient to rate each surgical goal (from 0 -10) in regards of its importance to them. 6.1. Rating helps everyone see which goals are the most important.

Step 7 Elicit the patient's psychosocial (lifestyle) goals and write them down on the PEGASUS sheet.

Step 8 Ask the patient to rate each psychosocial goal.

Step 9 Re-cap both surgical and psychosocial goals with importance ratings.

9.1. Show the patient the PEGASUS sheet and ask if there is anything they want to add.

Step 10 Instruct the patient to take the completed PEGASUS sheet into their consultation with the surgeon (part 2) and explain why this is important. 10.1. Take 2 photocopies ( 3 copies in all) of the PEGASUS sheet. Place a copy in the notes. Give a copy to the patient.

10.2. Is there anything else you want to ask?

Stage 2: the meeting between the surgeon and patient $\mathrm{t}^{\mathrm{b}}$

Step 1 Look at the completed PEGASUS sheet which contains your patients surgical and psychosocial goals and use it to facilitate a consultation that is focussed around the patients individual goals

Step 2 Rank (from 0 to 10) the probability of achieving each surgical goals and write this down on the PEGASUS sheet

Step 3 Reflect with the patient on the extent to which psychosocial goals are likely to follow. (Do not rank the probability of achieving psychosocial goals) $)^{\mathrm{c}}$

Step 4 Use the PEGASUS sheet along with your expert knowledge and experience of breast reconstruction surgery to identify if the patient has realistic expectations and then, if necessary, take steps to address and manage any that you consider to be unrealistic.

Place your PEGASUS sheet back in the patient's notes and ensure that the patient has her copy to take away

Step 5 At the patient's follow-up appointment (post-surgery) use the PEGASUS sheet once again to assist the discussion and reflect on the extent to which the surgical goals have been achieved

${ }^{a}$ Action: What you as the PEGASUS coach need to do

${ }^{\mathrm{b}}$ Action: What you as the surgeon need to do

${ }^{\mathrm{c}}$ Whilst surgeons are well placed to comment on the probability of achieving surgical goals, they do not know how these are likely to impact for any given individual. Interestingly, the National Audit report page 36 makes a similar distinction 'These results (on sexual satisfaction) are likely to reflect many issues that cannot be dealt with by the surgical team'

been preferable but the model was not in common use in the early stages of developing PEGASUS and we note the precedent in use of retrospectively coding BCTTv1 as part of the Theories and Techniques of Behaviour Change Project (www.ucl.ac.uk/health-psychology/research/TaT). Even used prospectively, the COM-B model has some difficulties. It assumes that problem behaviour is well understood and has been clearly identified and defined. In our study, this was facilitated via a robust data source and the intervention designed as a response to this. However, in considering requests to use PEGASUS with other patient groups, we have become aware of the problems that can arise where intervention development precedes assessment and understanding of the underlying problem. We would argue that shared decision-making should be viewed as a means to an end (increased satisfaction with outcome and the decision made) and not the goal of an intervention per se. Secondly, although COM-B is a systematic approach to behaviour change, there are a number of stages when decisions about intervention become subjective. For example, in choosing the sources of behaviour which seem to have the greatest potential utility and are the easiest to implement, judgments depend on the quality of information that can be accessed (for example from focus groups) or benefit from experience of researchers working within given systems or with particular client groups. The same criticism can be made about the objectiveness of selection of intervention functions, which are generally achieved via consensus as in this study. However, COM-B does allow greater rigour to be applied to the design of content of an intervention and thus 
rebalances the prevailing mismatch between intervention design and evaluation.

Our selection of shared decision-making and attempt to operationalise this can be criticised. Shared decision-making is a concept with many different definitions, and there is room for disagreement about the behaviours we selected to underpin this approach. However, we do have some preliminary evidence from the feasibility study that supports this choice [20]. Feedback was extremely positive - women found that completing PEGASUS alongside a discussion with a specially trained health professional helped them prepare for the surgical consultation and increased their trust in their surgeon. Staff reported that PEGASUS facilitated patient-centred discussions and informed the decisions made about potential surgery. PEGASUS is now undergoing a multicentre controlled trial to establish its effectiveness with a large patient group when compared with usual care and its potential impact on improving satisfaction with decision-making and outcome in breast reconstruction surgery [23]. Whilst data analysis in ongoing, early indications are that patients in the intervention group report a more positive experience in terms of organising their priorities at a time when they feel 'overwhelmed' by their diagnosis and express lower post-operative regret about the decisions they have made. Health professionals are similarly positive about the structure that PEGASUS provides for ensuring shared decision-making. If successful, we anticipate that it will have utility in other clinical settings.

Authors' contributions $\mathrm{AC}, \mathrm{EH}, \mathrm{DH}$ and NP co-designed the intervention. NP and PT trained the clinicians in using PEGASUS, collected feedback for revision and assisted in the application of COM-B. All authors contributed to drafting and editing the paper.

\section{Compliance with ethical standards}

Competing interests The authors declare that they have no conflict of interest.

Ethics approval Ethical approval for the evaluation of PEGASUS has been obtained from NRCS Committee South Central Berkshire-B (reference 15/SC/0331, the Faculty of health and Applied Science Research Ethics Committee at University of the West of England, Bristol and all necessary R\&D approvals have been obtained by NHS study sites. No additional ethical approval is needed for this report.

Open Access This article is licensed under a Creative Commons Attribution 4.0 International License, which permits use, sharing, adaptation, distribution and reproduction in any medium or format, as long as you give appropriate credit to the original author(s) and the source, provide a link to the Creative Commons licence, and indicate if changes were made. The images or other third party material in this article are included in the article's Creative Commons licence, unless indicated otherwise in a credit line to the material. If material is not included in the article's Creative Commons licence and your intended use is not permitted by statutory regulation or exceeds the permitted use, you will need to obtain permission directly from the copyright holder. To view a copy of this licence, visit http://creativecommons.org/licenses/by/4.0/.

\section{References}

1. National Mastectomy \& Breast Reconstruction Audit (2011) 4th annual report. Leeds: NHS Information Centre. https://digital.nhs. uk/data-and-information/publications/statistical/nationalmastectomy-and-breast-reconstruction-audit-annual-report. Accessed 02 Aug 2019

2. Lui D (2017) New plastic surgery statistics and breast reconstruction trends. ASPS. https://www.plasticsurgery.org/news/blog/newplastic-surgery-statistics-and-breast-reconstruction-trends. Accessed 02 Aug 2019

3. Teo I, Reece GP, Huang S-H, Mahajan K, Andon J, Khanal P, Sun C, Nicklaus K, Merchant F, Markey MK, Fingeret M (2018) Body image dissatisfaction in patients undergoing breast reconstruction: examining the roles of breast symmetry and appearance investment. Psycho-oncology 27(3):857-863. https://doi.org/10.1002/pon. 4586

4. Rumsey N, Harcourt D. (eds) (2012) The Oxford handbook of the psychology of appearance. OUP

5. Sheehan J, Sherman KA, LamT, Boyages, J (2007) Association of information satisfaction, psychological distress \& monitoring coping style with post-decision regret following breast reconstruction. Psycho-Oncology 16: 342-351.

6. Abu-Nab Z, Grunfeld EA (2007) Satisfaction with outcome and attitudes towards scarring among women undergoing breast reconstructive surgery. Patient Education and Counseling 66:243-249

7. MacInnes JA, Salkovskis P, Wroe A, Hope T (2015) Helping patients to reach decisions regarding their treatment: Do 'non-directive' approaches cause systematic bias? British Journal. Health Psychology 20(4):877-888. https://doi.org/10.1111/bjhp.12150

8. Elwyn G, Frosch D, Thomson R, Joseph-Williams N, Lloyd A, Kinnersley P, Cording E, Tomson D, Dodd C, Rollnick S, Edwards A, Barry M (2012) Shared decision-making: a model for clinical practice. J General Internal Medicine 27:1361-1367

9. Ubbink DT, Santema TB, Lapid O (2016) Shared decision-making in cosmetic medicine and aesthetic surgery. Aesthetic Surgery Journal 36:14-19

10. Stacey D, Kryworuchko J, Bennett C, Murray MA, Mullan S (2012) Decision coaching to prepare patients for making health decisions: a systematic review of decision coaching in trials of patient decision aids. Medical Decision-making 32:E22-E33. https://doi.org/10.1177/0272989X12443311

11. ZdenKowski N, Butow P, Tesson S, Boyle F (2016) A systematic review of decision aids for patients making a decision about treatment for early breast cancer. The Breast 26:31-45

12. Coulter A, Collins A (2000) Making shared decision-making a reality. No decision about me, without me London: King's Fund

13. Wroe AL, Salkovskis PM, Rees M, Jack T (2013) Information giving and Involvement in treatment decisions: Is more really better? Psychological effects and relation with adherence. Psychology \& Health 28:954-971. https://doi.org/10.1080/08870446.2013. 777964

14. Wight D, Wimbush E, Jepson R, Doi L (2016) Six steps in quality intervention development (6SQuID). J Epidemiology \& Community Health 70(5):520-525. https://doi.org/10.1136/jech2015-205952

15. Campbell M, Fitzpatrick R, Haines A, Kinmonth AL, Sandercock P, Spiegelhalter D, Tyrer P (2000) Framework for design and evaluation of complex interventions to improve health. BMJ 321:694 696

16. Craig P, Dieppe P, Macintyre S, Michie S, Nazareth I, Petticrew M (2008) Developing and evaluating complex interventions: the new Medical Research Council guidance. BMJ 337:a1655

17. Moore GF, Audrey S, Barker M, Bond L, Bonell C, Hardeman W, Moore L, O'Cathain A, Tinati T, Wight D, Baird J (2015) Process 
evaluation of complex interventions: Medical Research Council guidance. BMJ:350, h1258. https://doi.org/10.1136/bmj.h1258

18. Michie S, Van Straalen MM, West R (2011) The behaviour change wheel: a new method for characterising and designing behaviour change interventions. Implementation Science 6:16-42. https://doi. org/10.1186/1748-5908-6-42

19. Michie S, Atkins L, West R (2014) The behaviour change wheel. Silverback Publishing, A guide to designing interventions Kingston upon Thames

20. Harcourt D, Griffiths C, Baker E, Hansen E, White P, Clarke A (2016) The acceptability of PEGASUS: an intervention to facilitate shared decision-making with women contemplating breast reconstruction. Psychology, Health \& Medicine 21(2):248-253. https:// doi.org/10.1080/13548506.2015.1051059

21. Pusic AL, Klasen AF, Scott AM, Klok JA, Cordeiro PG, Cano SJ (2009) Development of a new patient-reported outcome measure for breast surgery: the BREAST-Q. Plastic \& Reconstructive Surgery 124(2):345-353. https://doi.org/10.1097/PRS. 0b013e3181aee 807

22. Timmerman L, Stronks DL, Huygen FGPM (2017) The design of a theory based intervention to improve medication adherence in chronic pain patients. Current Medical Research \& Opinion 33(7): 1293-1301. https://doi.org/10.1080/03007995.2017.1314955

23. Harcourt D, Paraskeva N, White P, Powell J, Clarke A (2017) A study protocol of the effectiveness of PEGASUS: a multi-centred study comparing an intervention to promote shared decisionmaking about breast reconstruction with treatment as usual. BMC Medical Informatics \& Decision-making 17:143

Publisher's Note Springer Nature remains neutral with regard to jurisdictional claims in published maps and institutional affiliations. 